\title{
Neuroimaging Findings in Patients with EBF3 Mutations: Report of Two Cases
}

\author{
Mar Jiménez de la Peña ${ }^{a}$ Ana Jiménez de Domingo ${ }^{b}$ Pilar Tirado ${ }^{c}$ \\ Beatriz Calleja-Pérez $^{d}$ Luis A. Alcaraz ${ }^{e}$ Sara Álvarez ${ }^{f}$ Jonathan Williams ${ }^{g}$ \\ James R. Hagman ${ }^{h}$ Andrea H. Németh ${ }^{i, j}$ Alberto Fernández-Jaén ${ }^{k}$
}

${ }^{a}$ Neuroimaging, Hospital Universitario Quirónsalud, Madrid, Spain; ${ }^{b}$ Department of Pediatric Neurology, Hospital Universitario Quirónsalud, Madrid, Spain; ' Department of Pediatric Neurology, Hospital Universitario La Paz, Madrid,

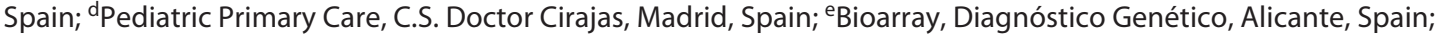
fGenomics and Medicine, NIMGenetics, Madrid, Spain; ${ }^{9}$ Oxford Medical Genetics Laboratories, Churchill Hospital, Oxford, UK; ' hepartment of Immunology and Genomic Medicine, National Jewish Health, Denver, CO, USA; 'Nuffield Department of Clinical Neurosciences, University of Oxford, Oxford, UK; jOxford Centre for Genomic Medicine, Oxford University Hospitals NHS Foundation Trust, Oxford, UK; kDepartment of Pediatric Neurology, Hospital Universitario Quirónsalud, and Medicine School, Universidad Europea de Madrid, Madrid, Spain

\section{Established Facts}

- Loss-of-function EBF3 mutations have been associated with an autosomal dominant neurodevelopmental disorder.

- Most affected cases have intellectual disability or autistic features.

- Cerebellar anomalies are described in $30 \%$ of the cases.

\section{Novel Insights}

- We describe 2 novel mutations in this syndrome.

- Intellectual disability was not observed in these 2 cases.

- Both cases showed short left superior longitudinal fasciculus and marked asymmetry of the inferior longitudinal fasciculus in 3D-tractography study

\section{Keywords}

EBF3 · Autism · ADHD · Neuroimaging · Tractography

\section{Abstract}

Early B cell factor 3 (EBF3) is a transcription factor involved in brain development. Heterozygous, loss-of-function muta- tions in EBF3 have been reported in an autosomal dominant neurodevelopmental syndrome characterized by hypotonia, ataxia, and developmental delay (sometimes described as "HADD"s). We report 2 unrelated cases with novel de novo EBF3 mutations: c.455G>T (p.Arg152Leu) and c.962dup (p. Tyr321*) to expand the genotype/phenotype correlations of this disorder; clinical, neuropsychological, and MRI studies karger@karger.com

(C) 2021 S. Karger AG, Basel

www.karger.com/msy

Karger ${ }^{\prime \prime}=$
Correspondence to:

Alberto Fernández-Jaén, aferjaen@ telefonica.net 
were used to define the phenotype. IQ was in the normal range and diffusion tensor imaging revealed asymmetric alterations of the longitudinal fasciculus in both cases. Our results demonstrate that $E B F 3$ mutations can underlie neurodevelopmental disorders without intellectual disability. Long tract abnormalities have not been previously recognized and suggest that they may be an unrecognized and characteristic feature in this syndrome.

๑) 2021 S. Karger AG, Basel

\section{Introduction}

The early B cell factor (EBF) family is composed of 4 proteins in mammals: EBF1-4. These proteins contain 4 cardinal domains: a Rel-like DNA-binding domain; the immunoglobulin, plexins, transcription factors-like/ transcription factor immunoglobulin (IPT/TIG) domain; an atypical helix-loop-helix motif, and a carboxy-terminal domain that contributes to DNA recognition, homodimerization and gene expression [Siponen et al., 2010; Treiber et al., 2010]. The DNA-binding domain, a zinc finger coordination motif, also participates in dimerization and transactivation; the function of IPT/TIG has not been determined yet, but it might regulate protein:protein interactions via homo- or heterodimerization; the helix-loop-helix motif is involved in dimerization, and the carboxy-terminal domain has a critical role in transcriptional activation [Garel et al., 1997; Liao, 2009; Green and Vetter, 2011a]. The EBF family of transcription factors is implicated in various aspects of neural development [Garel et al., 1997; Garcia-Dominguez et al., 2003; Green and Vetter, 2011a]. In particular, EBF3 is involved in neurogenesis. Its orthologs in Xenopus (xebf3) and mouse $(E b f 3)$ participate in neuronal differentiation and migration, and in muscle development [Pozzoli et al., 2001; Yamazaki et al., 2004; Green and Vetter, 2011b]. In 2017, over 20 cases with heterozygous loss-of-function mutations and intellectual disability, autism and/or global developmental delay were described [Blackburn et al., 2017; Chao et al., 2017; Harms et al., 2017; Lopes et al., 2017; Sleven et al., 2017; Tanaka et al., 2017; Murcia Pienkowski et al., 2019]. A series of cases is also present in the Deciphering Developmental Disorders database [Firth et al., 2009]. The mutations cause an autosomal dominant syndrome, with features including hypotonia, ataxia, and delayed development syndrome - MIM\# 617330. This supports the role of EBF3 in human brain development. However, the clinical features are broad and include strabismus, dysmorphic features and genito- urinary abnormalities, suggesting more pleiotropic effects.

The first EBF3 mutations to be described in patients with neurodevelopmental disorders were all de novo except for 2 families; a first family with 2 affected siblings with an inherited mutation from a healthy mother who had mosaicism for the EBF3 variant and a second family with affected mother and son, and no other affected individuals in the mother's family [Harms et al., 2017; Beecroft et al., 2020]. Missense, splice, frameshift, and nonsense mutations were described in these cases, and the majority of missense mutations are in or near the zincfinger motif of the DNA-binding domain. Most cases were reported to have (1) intellectual disability or global developmental delay, (2) ADHD or autistic features, (3) motor delay or cerebellar ataxia, and (4) associated dysmorphic features [Blackburn et al., 2017; Chao et al., 2017; Harms et al., 2017; Lopes et al., 2017; Sleven et al., 2017; Tanaka et al., 2017]. Structural brain abnormalities are infrequent in these cases; vermis hypoplasia, delayed myelination, and subtle migration disorders have been previously reported in this syndrome. Overall, 50\% of the cases were reported to have normal standard $3 \mathrm{~T}$ brain MRIs [Firth et al., 2011; Chao et al., 2017; Harms et al., 2017; Tanaka et al., 2017; D’Arrigo et al., 2020].

Here, we describe 2 cases with de novo EBF3 mutations in which intellectual disability was absent, but the individuals had autistic features and ADHD. In both individuals, standard brain imaging was normal, but diffusion tensor imaging (DTI) tractography revealed asymmetry of the superior and inferior longitudinal fasciculus.

\section{Case Presentation}

Identification of Mutations in the EBF3 Gene

We reviewed 390 cases of trio exome sequencing performed in our department since 2014, searching for EBF3 mutations. All studies were performed on patients with neurodevelopmental disorders of probable genetic origin. We identified 2 unrelated cases with novel mutations in EBF3.

Clinical Features of the Patients and Previous Diagnostic Studies

Case 1

The individual is a 14-year-old male, the first child of healthy parents of Spanish origin. There was no relevant family history. Early motor delay was noted, but verbal development was normal, with first clear words at 12 months. At age 6 neuropsychological evaluation revealed a Full-Scale Intelligence Quotient (FSIQ) of 93 in WISC-IV, with very low attention abilities. School performance and social interactions were good, but empathy was poor. There were no stereotypies or restricted interests. 

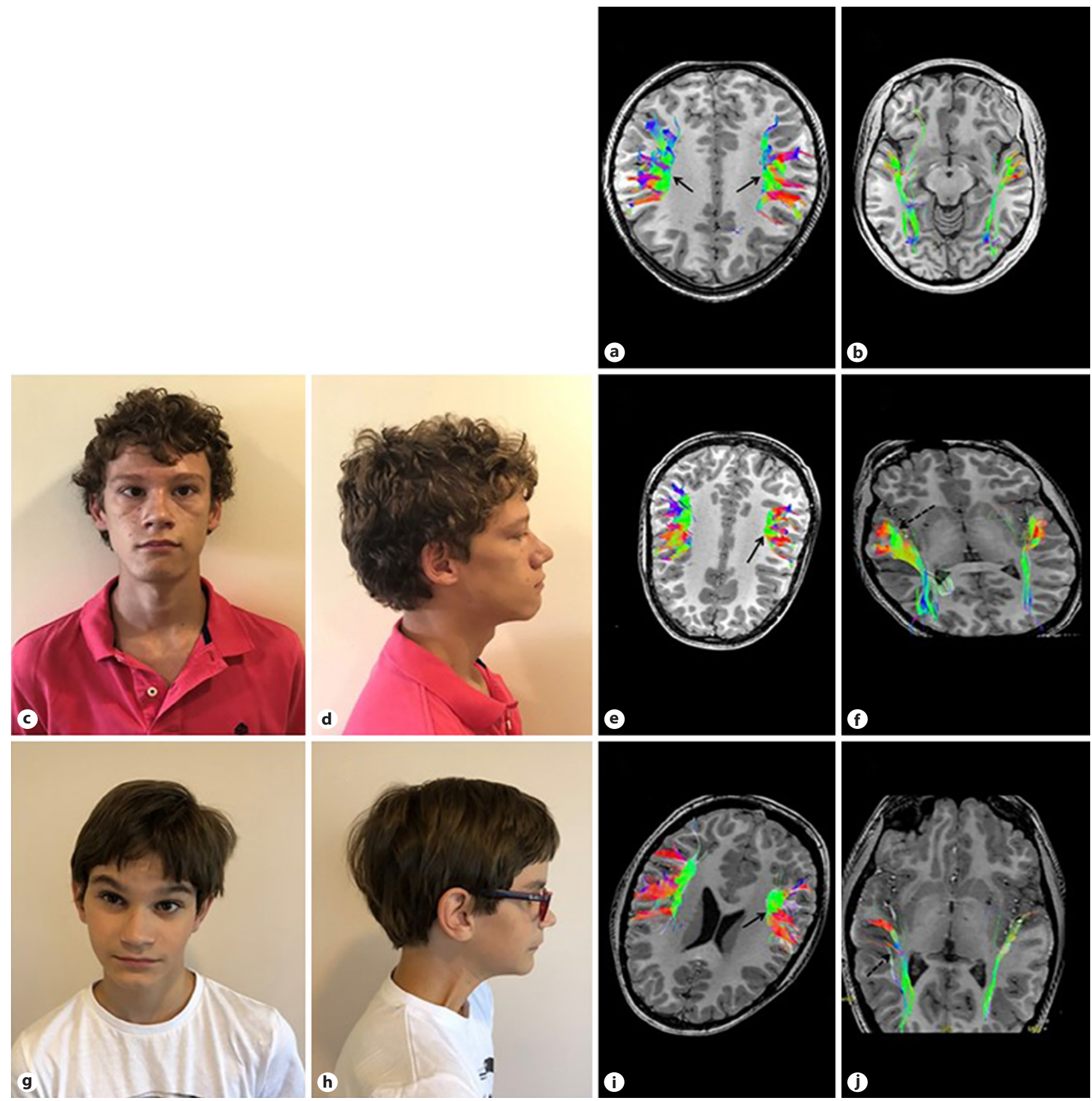

Fig. 1. a, b 3D-tractography reconstruction in healthy control. a Symmetric superior longitudinal fasciculus with a prominent frontoparietal component colored in green of equal length (black arrows). b Symmetric superior longitudinal fasciculus with a prominent frontoparietal component colored in green of equal length. c, d Facial appearance of Individual 1. Long face, upslanting palpebral fissures, almond-shaped eyes, strabismus, deep philtrum, broad chin. e, f 3D-tractography reconstruction in Individual 1. e Short frontoparietal component of the left superior longitudinal fascicle (arrow). f Enlarged right inferior longitudinal fascicle (dashed black arrow). $\mathbf{g}, \mathbf{h}$ Facial appearance of Individual 2. Long face, tall forehead, arched eyebrows, upslanting palpebral fissures, almond-shaped and deep-set eyes, strabismus, deep philtrum, wide mouth, thin upper lip, short and broad chin, chin dimple. $\mathbf{i}, \mathbf{j}$ 3D-tractography reconstruction in Individual 2. i Asymmetry of the left superior longitudinal fasciculus. The frontoparietal component colored in green is short (black arrow) and the frontal opercular fibers, colored in red, present a more horizontal course. $\mathbf{j}$ Asymmetry of the right inferior longitudinal fascicle, similar to case 1. Diffuse enlargement of the right tract (dashed arrow). 
Physical examination revealed a weight of $17 \mathrm{~kg}$ (50th centile), height of $102 \mathrm{~cm}$ (45th centile), and OFC of $51 \mathrm{~cm}$ (50th centile). Some dysmorphic features were observed: almond-shaped eyes with upslanting palpebral fissures, a triangular face, bulbous nose, and pointed chin (Fig. 1c, d ). The patient also exhibited severe coordination problems, strabismus, and dysprosodic speech, with good vocabulary and comprehension.

Routine laboratory screening including thyroid function and neurometabolic tests were within the normal range. Sleep videoEEG test and auditory evoked potentials displayed normal results. Brain 1.5T MRI at age 4 and 3T MRI at age 14 did not reveal any significant structural malformations. Conventional genetic studies (karyotyping and array-CGH analysis) revealed no abnormalities.

\section{Case 2}

The individual is an 11-year-old male, who is the second child of healthy parents of Spanish origin. There was no relevant family history. Global hypotonia was observed in the first 2 years of life. The patient walked unsupported at 19 months. Verbal development was mildly delayed. Clinical examination revealed a weight of $36 \mathrm{~kg}$ (50th centile), height of $148 \mathrm{~cm}$ (75th centile), and OFC of $52 \mathrm{~cm}$ (50th centile). Strabismus and dysmorphic features were observed: arched eyebrows, almond-shaped eyes with upslanting palpebral fissures, triangular face, bulbous nose, wide mouth and pointed chin (Fig. 1g, h).

Physical examination showed significant difficulties in fine and gross motor skills; during the evaluation, he was sociable and affectionate. Overall communication was good, no difficulties in expression or comprehension were observed; his vocabulary and prosody were normal. However, there were problems with the pragmatics of language.

Conventional genetic studies (karyotyping and array-CGH analysis) revealed no abnormalities. The neuropsychological evaluation demonstrated a General Ability Index of 89 and an IQ of 85 in Toni-2. Specific problems in working memory, attention abilities, and cognitive empathy were noted. 3T brain MRI showed no structural anomalies.

\section{Materials and Methods}

\section{Genetic Analysis}

Exome sequencing was performed using genomic DNA isolated from whole blood from the proband and parents (MagNaPure, Roche). Libraries were prepared using the Ion AmpliSeq ${ }^{\mathrm{TM}}$ Exome Kit (Life Technologies, Carlsbad, CA, USA) and quantified by qPCR. The enriched libraries were prepared using Ion Chef ${ }^{\mathrm{TM}}$ and sequenced on PI ${ }^{\mathrm{TM}}$ Chip in the Ion Proton ${ }^{\mathrm{TM}}$ System (Life Technologies) to provide $>90 \%$ of amplicons with at least 20X coverage. Signal processing, base calling, alignment, and variant calling were performed on a Proton ${ }^{\mathrm{TM}}$ Torrent Server using the Torrent Suite ${ }^{\mathrm{TM}}$ Software. Variants were annotated using Ion Reporter ${ }^{\mathrm{TM}}$ Software, and pedigree analysis was performed using the Genetic Disease Screen (GDS) trio workflow. Variant filtering and prioritization were performed using an in-house software program and a local database. Candidate variants were visualized using IGV (Integrative Genomics Viewer). Candidate variants were evaluated based on stringent assessments at both the gene and variant levels, taking into consideration both the patient's phenotype and the inheritance pattern. Variants were classified following the guidelines of the American College of Medical Genetics and Genomics (ACMG). A board of molecular clinical geneticists evaluated each variant classified as pathogenic, likely pathogenic, or variant of uncertain significance, and decided which, if any, had to be reported. In every case, causal variants were discussed with the referring physician and/or clinical geneticist. Identified variants were confirmed by Sanger sequencing.

\section{Neuroimaging}

DTI images were obtained with a 3T system (GE Medical System, Milwaukee, WI, USA) by using a SS-SE echoplanar diffusionweighted image sequence (TR:12,000; FOV: $240 \mathrm{~mm}$; sections thickness: $3 \mathrm{~mm}$, 0 spacing; matrix $128 \times 128$; bandwith: 250; 1 nex; diffusion encoding in 45 directions) with maximum $\mathrm{b}=1,000 \mathrm{~s} /$ $\mathrm{mm}^{2}$.

3D tractography was performed in an off-line workstation by using commercially available processing software as provided by the manufacturer (Functool 3D Fiber Tracking, GE, France) based on fiber assignment by contiguous tracking (FACT) method, achieved by connecting voxel to voxel. The threshold values were 0.3 for $\mathrm{FA}$ and $45^{\circ}$ for the trajectory angles, between the regions of interest. DTI tracts were also co-registered to the $3 \mathrm{D}$ T1-weighted data set.

\section{Results}

Whole-exome trio analysis revealed a de novo missense mutation in exon 5 of EBF3: hg19; Chr10:131,757,228; NM_001005463.2; c.455G>T (p.Arg152Leu) in the first case. This is the first mutation at position p.Arg152 to be reported and is located within the DNA-binding domain of EBF3, where other missense mutations are located [Chao et al., 2017; Harms et al., 2017; Sleven et al., 2017]; in silico predictors (SIFT, PROVEAN, MutationTaster, REVEL, and LRT) describe it as pathogenic. A de novo frameshift mutation in exon 10 of EBF3: hg19, g.131665455dup; c.962dup (p.Tyr321*) was present in Case 2. This mutation is predicted to cause loss of function, as reported in some other cases [Harms et al., 2017; Sleven et al., 2017; Tanaka et al., 2017]. Neither of these mutations has been previously described in healthy controls according to international databases.

In Case 1, DTI tractography at age 14 revealed a short left superior longitudinal fascicle and an enlarged right inferior longitudinal fascicle (Fig. 1e, f). In the second case, 3D tractography reconstruction demonstrated a marked asymmetry of both superior and inferior longitudinal fasciculus (Fig. 1i, $\mathrm{j}$ ). 
Table 1. Neuroimaging findings in patients with $E B F 3$ mutations described as pathogenic

\begin{tabular}{|c|c|c|c|}
\hline Reference & $\begin{array}{l}\text { Number } \\
\text { of cases }\end{array}$ & MRI findings & $\begin{array}{l}\text { Cases with abnormal } \\
\text { brain MRI/cases with } \\
\text { performed and } \\
\text { available results* }\end{array}$ \\
\hline This report & 2 & $\begin{array}{l}1 \text { case: no significant structural malformations. DTI tractography: Short } \\
\text { left superior longitudinal fascicle and an enlarged right inferior } \\
\text { longitudinal fascicle } \\
1 \text { case: no significant structural malformations. DTI tractography: } \\
\text { Marked asymmetry of both superior and inferior longitudinal fasciculi }\end{array}$ & $2 / 2$ \\
\hline Blackburn et al., 2017 & 1 & Normal MRI & $0 / 1$ \\
\hline Sleven et al., 2017 & 2 & Normal MRI & $0 / 2$ \\
\hline Chao et al., 2017 & 3 & $\begin{array}{l}1 \text { case: normal MRI } \\
1 \text { case: cerebellar vermis hypoplasia and reduced cerebellar hemisphere } \\
\text { volumes } \\
1 \text { case: cerebellar vermis hypoplasia }\end{array}$ & $2 / 3$ \\
\hline Tanaka et al., 2017 & 7 & $\begin{array}{l}1 \text { case: not available } \\
3 \text { cases: normal MRI } \\
1 \text { case: cerebellar vermis hypoplasia } \\
1 \text { case: small schizencephalic cleft in right temporal lobe and delayed } \\
\text { myelination at } 2 \text { years, later resolved } \\
1 \text { case: curvilinear tract-like signal abnormality in left frontal cerebral } \\
\text { white matter and protuberance of right optic papillae }\end{array}$ & $3 / 6$ \\
\hline Harms et al., 2017 & 10 & $\begin{array}{l}6 \text { cases: normal MRI } \\
2 \text { cases: not available } \\
2 \text { cases: cerebellar vermis hypoplasia }\end{array}$ & $2 / 8$ \\
\hline Decipher, 2020 & 18 & $\begin{array}{l}7 \text { cases: not available } \\
2 \text { cases: cerebellar dysplasia } \\
1 \text { case: dysplastic corpus callosum } \\
1 \text { case: delayed CNS myelination } \\
1 \text { case: cerebellar dysplasia and delayed CNS myelination }\end{array}$ & $5 / 5$ \\
\hline Beecroft et al., 2020 & 2 & 2 cases: not available & - \\
\hline D’Arrigo et al., 2020 & 1 & 1 case: cerebellar hypoplasia (dandelion cerebellar sign) & $1 / 1$ \\
\hline
\end{tabular}

\section{Discussion}

We report 2 novel mutations in EBF3. Attention deficit and behavior problems were observed in both cases, associated with some autistic features; neuropsychological evaluation showed no intellectual disability. Facial dysmorphism and some clinical features in both cases were similar to others in the literature [Blackburn et al., 2017; Chao et al., 2017; Harms et al., 2017; Lopes et al., 2017; Sleven et al., 2017; Tanaka et al., 2017].

The clinical features reported to be associated with EBF3 mutations include global psychomotor and lan- guage delay, hypotonia, intellectual disability, autism, behavioral problems, cerebellar ataxia, and dysmorphic features [Blackburn et al., 2017; Chao et al., 2017; Harms et al., 2017; Lopes et al., 2017; Sleven et al., 2017; Tanaka et al., 2017]. Intellectual disability, attention/behavior problems and autistic features have been described in 28,90 , 43 , and $57 \%$ of the cases, respectively [Blackburn et al., 2017; Chao et al., 2017; Harms et al., 2017; Sleven et al., 2017; Tanaka et al., 2017]. The frequencies of the different neurodevelopmental disorders in this syndrome are conditioned by the selection of the populations studied in described series. However, our cases and those in previ- 
ous reports demonstrate that the neurodevelopmental phenotype does not necessarily include intellectual disability, but may include more prominent behavioral disturbances such as autism and ADHD.

The other key finding of this study was the abnormal 3D tractography with short left superior longitudinal fascicle and marked asymmetry of the inferior longitudinal fasciculus. This adds a new dimension to the investigation of EBF3 in neurodevelopment, as this has not been reported in humans, nor in animal models. Given the functions of EBF3 in brain development, the low frequency of structural brain abnormalities is intriguing; cerebellar hypoplasia, delayed myelination, and mild migration disorders have been described in 30,12 , and $8 \%$ of the cases, respectively, with performed and available MRI (Table 1) [Firth et al., 2011; Chao et al., 2017; Harms et al., 2017; Tanaka et al., 2017; D’Arrigo et al., 2020]. No macroscopic malformations were observed in our cases either. However, 3D tractography reconstruction revealed the same features in both boys.

The superior fasciculus are involved in language, attention, and emotion [Conner et al., 2018], while the inferior fasciculus function in emotional regulation and semantic and visual processing [Herbet et al., 2018; Sali et al., 2018]. Poor development of the left superior longitudinal fasciculus has been described in autism and language disorders [Verhoeven et al., 2012; Aoki et al., 2013; Boets et al., 2018; Verly et al., 2019]. The asymmetric development of the inferior longitudinal fasciculus has been found in $\mathrm{ADHD}$, language disorders, and autism [Roine et al., 2015; Svatkova et al., 2016]. These abnormalities have only been detected using DTI processing.

Analyzing the possible correlation between genotype and phenotype according to previously published cases, we found that $45 \%$ of the patients with missense mutations in the DNA-binding domain had structural abnormalities in brain MRI, compared to $40 \%$ of the patients with frameshift or nonsense mutations [Blackburn et al., 2017; Chao et al., 2017; Harms et al., 2017; Sleven et al., 2017; Tanaka et al., 2017]. When assessing the cognitive status of the cases, $70 \%$ of the patients with missense mutations in this domain showed some degree of intellectual disability, paradoxically compared to $50 \%$ of the patients with other types of mutations. The presence of mutations in other domains of this gene has been described in more exceptional cases, of which $30 \%$ showed brain structural abnormalities and/or intellectual disability. Forty-four percent of the cases with intellectual disability showed brain malformations, but the remaining $56 \%$ had no notable alterations in MRIs, which suggests the pres- ence of possible cortical or white matter microstructural defects.

White matter microstructure alterations have been scarcely studied in genetic disorders. Most of the studies with DTI have been reported in patients with microdeletions or other well-known syndromes. Thus, asymmetries in the inferior and superior longitudinal fasciculus have been previously described in 22q11.2 microdeletion syndrome [Jalbrzikowski et al., 2014], frequently characterized by the presence of ADHD or autism spectrum disorders [McDonald-McGinn et al., 2020]. In contrast, in 16 p11.2 deletion syndrome, a more relevant involvement has been reported in the uncinate and arcuate fasciculus [Ahtam et al., 2019]; the selective involvement of the language networks could explain the high frequency of language disorders and autism in this syndrome [Miller et al., 2015]. These findings are comparable to the results observed in patients with Angelman syndrome, who show the involvement of the uncinate, arcuate and inferior longitudinal fasciculus [Peters et al., 2011]. Mahmood et al. [2010] demonstrated the participation of the superior longitudinal fascicle in patients with nonverbal Rett syndrome, but not in patients with preserved language; this group points to DTI as a neuroimaging technique that may provide relevant information in the severity evaluation and phenotyping of these cases.

The anomalies we describe might be caused by microstructural cortical defects or by a disturbance in both axonal and myelin development [Wahl et al., 2010; Poretti et al., 2013]. The function of EBF3 in the developing human brain remains to be fully elucidated, and our study illustrates that further work is required to determine if structural connectivity is widely disturbed in individuals with EBF3 mutations and to understand its developmental basis.

\section{Acknowledgement}

We thank both families for their participation and helpful cooperation in this study.

\section{Statement of Ethics}

This study complied with the guidelines for human studies and was conducted in accordance with the World Medical Association Declaration of Helsinki and approved by the Local Ethics Committees. Written informed consent was obtained from both families to publish these cases (including publication of images). 


\section{Conflict of Interest Statement}

The authors have no conflicts of interest to declare.

\section{Funding Sources}

No targeted funding was used.

\section{Author Contributions}

M. Jiménez: acquisition and analysis of MRI images. A. Jiménez, P. Tirado, and B. Calleja: study concept and design. L.A. Alcaraz, S. Álvarez, and J. Williams: acquisition and analysis of genetic data. J.R. Hagman, A.H. Nemeth, and A. Fernández-Jaén: study concept and design, study supervision, and critical revision of the manuscript for intellectual content.

\section{References}

Ahtam B, Link N, Hoff E, Grant PE, Im K. Altered structural brain connectivity involving the dorsal and ventral language pathways in 16 p11.2 deletion syndrome. Brain Imaging Behav. 2019;13(2):430-45.

Aoki Y, Abe O, Nippashi Y, Yamasue H. Comparison of white matter integrity between autism spectrum disorder subjects and typically developing individuals: A meta-analysis of diffusion tensor imaging tractography studies. Mol Autism. 2013;4(1):25.

Beecroft SJ, Olive M, Quereda LG, Gallano P, Ojanguren I, McLean C, et al. Cylindrical spirals in two families: Clinical and genetic investigations. Neuromuscul Disord. 2020; 30(2):151-8.

Blackburn PR, Barnett SS, Zimmermann MT, Cousin MA, Kaiwar C, Pinto E, Vairo F, et al. Novel de novo variant in EBF3 is likely to impact DNA binding in a patient with a neurodevelopmental disorder and expanded phenotypes: Patient report, in silico functional assessment, and review of published cases. Cold Spring Harb Mol Case Stud. 2017;3(3): a001743.

Boets B, Van Eylen L, Sitek K, Moors P, Noens I, Steyaert J, et al. Alterations in the inferior longitudinal fasciculus in autism and associations with visual processing: A diffusionweighted mri study. Mol Autism. 2018;9:10.

Chao HT, Davids M, Burke E, Pappas JG, Rosenfeld JA, McCarty AJ, et al. A syndromic neurodevelopmental disorder caused by de novo variants in ebf3. Am J Hum Genet. 2017; 100(1):128-37.

Conner AK, Briggs RG, Rahimi M, Sali G, Baker CM, Burks JD, et al. A connectomic atlas of the human cerebrum-chapter 10: Tractographic description of the superior longitudinal fasciculus. Oper Neurosurg (Hagerstown). 2018;15(suppl 1):S407-S422.

D’Arrigo S, Moscatelli M, Ciaccio C, Pantaleoni C, Castello R, Chiapparini L, et al. Abnormal cerebellar foliation in EBF3 mutation. Neurology. 2020;94(21):933-5.

Firth HV, Richards SM, Bevan AP, Clayton S, Corpas M, Rajan D, et al. Decipher: Database of chromosomal imbalance and phenotype in humans using ensembl resources. Am J Hum Genet. 2009;84(4):524-33.

Firth HV, Wright CF, DDDStudy . The deciphering developmental disorders (DDD) study. Dev Med Child Neurol. 2011;53(8):702-3.
Garcia-Dominguez M, Poquet C, Garel S, Charnay $\mathrm{P}$. Ebf gene function is required for coupling neuronal differentiation and cell cycle exit. Development. 2003;130(24):6013-25.

Garel S, Marín F, Mattéi MG, Vesque C, Vincent A, Charnay P. Family of Ebf/Olf-1-related genes potentially involved in neuronal differentiation and regional specification in the central nervous system. Dev Dyn. 1997; 210(3):191-205.

Green YS, Vetter ML. EBF factors drive expression of multiple classes of target genes governing neuronal development. Neural Dev. 2011a;6:19.

Green YS, Vetter ML. EBF proteins participate in transcriptional regulation of Xenopus muscle development. Dev Biol. 2011b;358(1):24050.

Harms FL, Girisha KM, Hardigan AA, Kortüm F, Shukla A, Alawi M, et al. Mutations in EBF3 disturb transcriptional profiles and cause intellectual disability, ataxia, and facial dysmorphism. Am J Hum Genet. 2017;100(1):11727.

Herbet G, Zemmoura I, Duffau H. Functional anatomy of the inferior longitudinal fasciculus: From historical reports to current hypotheses. Front Neuroanat. 2018;12:77.

Jalbrzikowski M, Villalon-Reina JE, Karlsgodt $\mathrm{KH}$, Senturk D, Chow C, Thompson PM, et al. Altered white matter microstructure is associated with social cognition and psychotic symptoms in 22q11.2 microdeletion syndrome. Front Behav Neurosci. 2014;8:393.

Liao D. Emerging roles of the EBF family of transcription factors in tumor suppression. Mol Cancer Res. 2009;7(12):1893-901.

Lopes F, Soares G, Gonçalves-Rocha M, PintoBasto J, Maciel P. Whole gene deletion of EBF3 supporting haploinsufficiency of this gene as a mechanism of neurodevelopmental disease. Front Genet. 2017;8:143.

Mahmood A, Bibat G, Zhan AL, Izbudak I, Farage L, Horska A, et al. White matter impairment in rett syndrome: Diffusion tensor imaging study with clinical correlations. Am J Neuroradiol. 2010;31(2):295-9.

McDonald-McGinn DM, Hain HS, Emanuel BS, Zackai EH. 22q11.2 deletion syndrome. In: Adam MP, Ardinger HH, Pagon RA, Wallace SE, Bean LJH, Stephens K, Amemiya A, editors. GeneReviews. [Internet] University of Washington, Seattle; 1993-2021. Initial post- ing: Sept. 23, 1999; last update:. GeneReviews; Feb. 27, 2020.

Miller DT, Chung W, Nasir R, Shen Y, Steinman $\mathrm{KJ}, \mathrm{Wu} \mathrm{BL}$, et al. 16p11.2 recurrent microdeletion. In: Adam MP, Ardinger HH, Pagon RA, Wallace SE, Bean LJH, Stephens K, Amemiya A, editors. GeneReviews. [Internet] University of Washington, Seattle; 19932021. Initial posting: Sept. 22, 2009; last update:. GeneReviews; Dec. 10, 2015.

Murcia Pienkowski V, Kucharczyk M, Młynek M, Szczałuba K, Rydzanicz M, Poszewiecka B, et al. Mapping of breakpoints in balanced chromosomal translocations by shallow whole-genome sequencing points to EFNA5, BAHD1 and PPP2R5E as novel candidates for genes causing human mendelian disorders. J Med Genet. 2019;56(2):104-12.

Peters SU, Kaufmann WE, Bacino CA, Anderson AW, Adapa P, Chu Z, et al. Alterations in white matter pathways in angelman syndrome. Dev Med Child Neurol. 2011;53(4):361-7.

Poretti A, Meoded A, Rossi A, Raybaud C, Huisman TA. Diffusion tensor imaging and fiber tractography in brain malformations. Pediatr Radiol. 2013;43(1):28-54.

Pozzoli O, Bosetti A, Croci L, Consalez GG, Vetter ML. Xebf3 is a regulator of neuronal differentiation during primary neurogenesis in Xenopus. Dev Biol. 2001;233(2):495-512.

Roine U, Salmi J, Roine T, Wendt TN, Leppämäki S, Rintahaka P, et al. Constrained spherical deconvolution-based tractography and tractbased spatial statistics show abnormal microstructural organization in asperger syndrome. Mol Autism. 2015;6:4.

Sali G, Briggs RG, Conner AK, Rahimi M, Baker CM, Burks JD, et al. A connectomic atlas of the human cerebrum-chapter 11: Tractographic description of the inferior longitudinal fasciculus. Oper Neurosurg (Hagerstown). 2018;15(suppl 1):S423-S428.

Siponen MI, Wisniewska M, Lehtiö L, Johansson I, Svensson L, Raszewski G, et al. Structural determination of functional domains in early b-cell factor (EBF) family of transcription factors reveals similarities to rel DNA-binding proteins and a novel dimerization motif. J Biol Chem. 2010;285(34):25875-9.

Sleven H, Welsh SJ, Yu J, Churchill MEA, Wright $\mathrm{CF}$, Henderson A, et al. De novo mutations in EBF3 cause a neurodevelopmental syndrome. Am J Hum Genet. 2017;100(1):138-50. 
Svatkova A, Nestrasil I, Rudser K, Goldenring Fine J, Bledsoe J, Semrud-Clikeman M. Unique white matter microstructural patterns in adhd presentations-a diffusion tensor imaging study. Hum Brain Mapp. 2016;37(9): 3323-36.

Tanaka AJ, Cho MT, Willaert R, Retterer K, Zarate $\mathrm{YA}$, Bosanko $\mathrm{K}$, et al. De novo variants in EBF3 are associated with hypotonia, developmental delay, intellectual disability, and autism. Cold Spring Harb Mol Case Stud. 2017; $3(6)$.
Treiber N, Treiber T, Zocher G, Grosschedl R. Structure of an Ebf1:DNA complex reveals unusual DNA recognition and structural homology with rel proteins. Genes Dev. 2010; 24(20):2270-5.

Verhoeven JS, Rommel N, Prodi E, Leemans A, Zink I, Vandewalle $\mathrm{E}$, et al. Is there a common neuroanatomical substrate of language deficit between autism spectrum disorder and specific language impairment? Cereb Cortex. 2012;22(10):2263-71.

Verly M, Gerrits R, Sleurs C, Lagae L, Sunaert S, Zink I, et al. The mis-wired language network in children with developmental language disorder: Insights from DTI tractography. Brain Imaging Behav. 2019;13(4):973-84.
Wahl M, Barkovich AJ, Mukherjee P. Diffusion imaging and tractography of congenital brain malformations. Pediatr Radiol. 2010;40(1): 59-67.

Yamazaki H, Sekiguchi M, Takamatsu M, Tanabe Y, Nakanishi S. Distinct ontogenic and regional expressions of newly identified cajalretzius cell-specific genes during neocorticogenesis. Proc Natl Acad Sci USA. 2004; 101(40):14509-14. 